\title{
Four Major Bottlenecks in Cross-Border Electricity Suppliers Need to Be Resolved
}

\author{
Chen Ping ${ }^{1}$, Zhu Baohui ${ }^{2}$ \\ ${ }^{1}$ Chengdu Information Engineering University of Ginkgo Hotel Management College, Chengdu City, China \\ ${ }^{2}$ Chengdu acceleration Electricity Business Incubator Co., Ltd., Chengdu City, China \\ Email address: \\ xkm02@163.com (Chen Ping), zhc019@163.com (Zhu Baohui)
}

\section{To cite this article:}

Chen Ping, Zhu Baohui. Four Major Bottlenecks in Cross-Border Electricity Suppliers Need to Be Resolved. International Journal of Economics, Finance and Management Sciences. Vol. 3, No. 6, 2015, pp. 668-671. doi: 10.11648/j.ijefm.20150306.12

\begin{abstract}
The article through a large number of cross-border electricity suppliers data and analysis, through cooperation with Alibaba and Astor cross-border electricity suppliers, deeply felt the current development of cross-border electricity suppliers, four major bottlenecks to be solved. For cross-border business, data and the prospects although very beautiful, but deep inside engaged in this industry will quickly find, practitioners can truly benefit from these data in a molecule, there does not seem to be so simple as it looks, cross-border explosive growth of online shopping, the international trade, cross-border logistics transportation, warehousing, distribution, cross-border settlement service, this paper puts forward a very severe test, and subsequent after-sales, returned goods, cross-border credit, risk and highlighted gradually, become the bottleneck problem of cross-border business development. To make cross-border electricity suppliers industry healthy and stable development, the need to address the four major bottlenecks and related problems.
\end{abstract}

Keywords: Cross-Border, International Trade, Customs Clearance Settlement, Logistics Transportation

\section{跨境电商亟待解决的四大瓶颈问题}

\author{
陈平 ${ }^{1}$, 朱宝慧 ${ }^{2}$ \\ 1 成都信息工程大学银杏酒店管理学院电商系, 成都市, 中国 \\ ${ }^{2}$ 成都加速度电商孵化有限公司, 成都市, 中国
}

\begin{abstract}
摘要：文章通过大量的跨境电商数据及分析研究，通过与阿里巴巴和阿斯特跨境电商的合作，深切感受到目前跨境电 商的发展, 亟待解决四大瓶颈问题。对于跨境电商来说, 数据和前景虽然很美, 但深入进去从事这一行业会迅速发现, 从业者是否能真正成为这些数据中受益的一分子，似乎没有看上去那么简单，跨境电商的爆发式增长对网购、国际贸 易、跨境物流运输、仓储配送、跨境结算等服务，提出了极为严峻的考验，以及其后的售后、退换货、跨境电商信用、 风险等问题逐渐凸显，成为制约跨境电商发展的瓶颈问题。要使跨境电商行业健康稳定的发展，亟待解决四大瓶颈问 题以及相关配套问题。
\end{abstract}

关键词：跨境电商, 国际贸易, 通关结汇, 物流运输

\section{1. 引言}

自2014年以来，跨境电商进口试点正如火如茶，今 年6月10日利好再出, 发自中国国务院《关于促进跨境电 子商务健康快速发展的指导意见》, 强调促进跨境电商
健康快速发展, 用 “互联网+外贸” 实现优进优出, 有利 于扩大消费, 推动开放型经济的发展升级, 打开新的经 济增长契机。

从跨境电商交易额的角度来分析，2012年，中国外贸 进出口已经超过美国, 成为世界进出口贸易规模最大的国 
家, 而其中跨境电商贸易增长更加迅猛。2013年, 中国跨 境电商交易额达到了 2.7 万亿元，同比增长 $29 \%$, 超出同期 传统贸易总额发展速度5倍以上。2014年，中国跨境电商交 易规模为 4.2 万亿元, 增长率为 $35.48 \%$, 占进出口贸易总额 的 $15.89 \%$ 。联合国贸发会议预计，2015年，跨境电商将占 世界贸易总额的 $30 \% \sim 40 \%$ ，在此后的几年里，这一比例还
有可能继续攀升, 到 “十二五” 时期末, 中国跨境电商交 易额占进出口总值的比例将达到 $16.9 \%$, 据商务部测算, 2016年, 中国跨境电商交易规模将从 2008 年的 0.8 万亿元增 长到 6.5 万亿元, 占整个外贸规模的 $19 \%$, 年均增速接近 $30 \%$ 。 而根据艾瑞的预测, 2017年中国跨境电商规模将达到 8 万亿 元, 平均增速超过 $26 \%$, 行业无疑处于高速增长期。

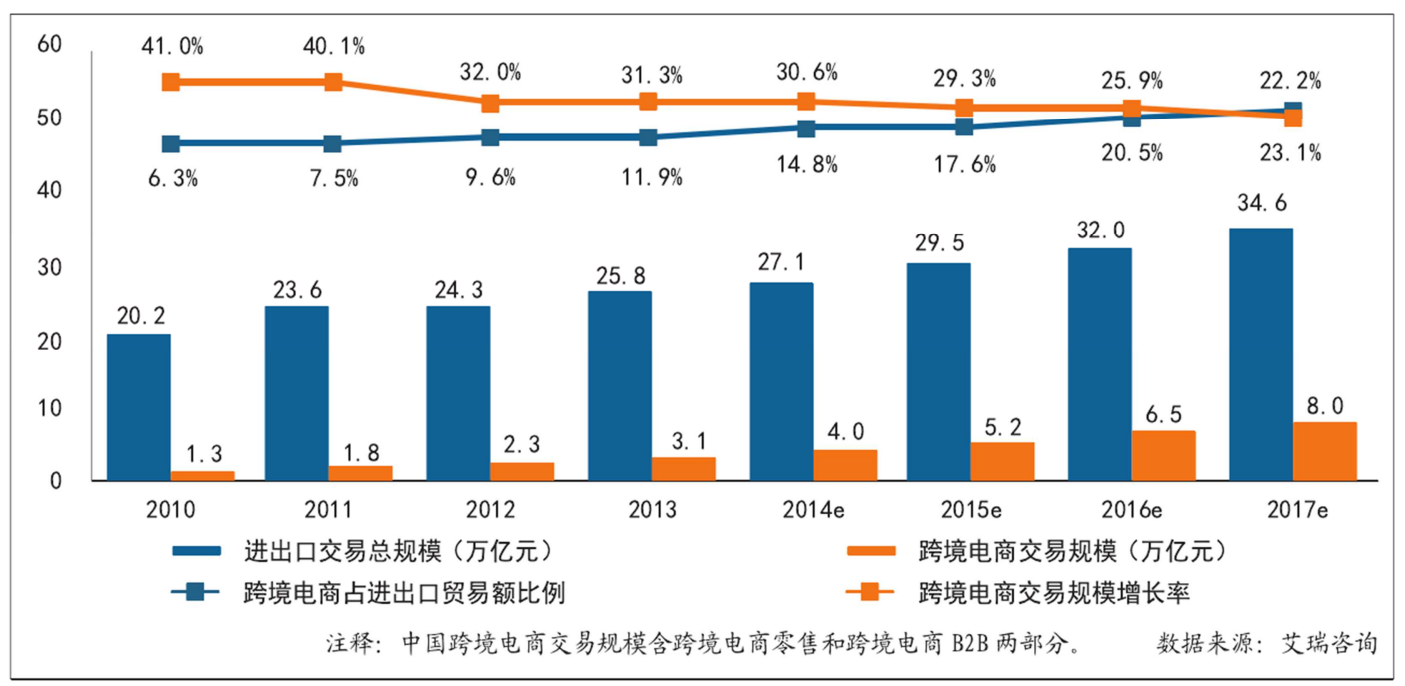

图1 2010-2017年中国进出口贸易及跨境电商交易规模。

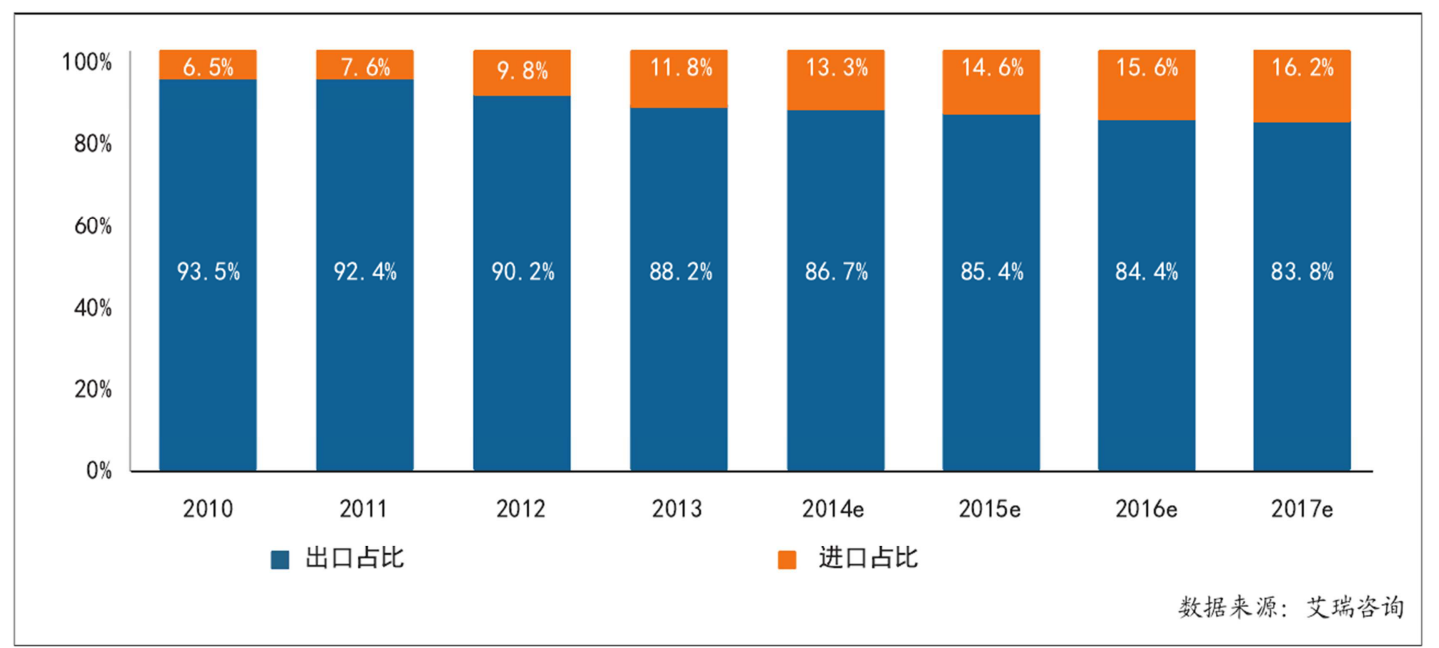

图2 2010-2017年中国跨境电商交易规模进出口结构。

让我们再来看一组数据, 2013年7月24日, ebay旗下 的在线支付平台PayPal发布了首份全球跨境电子商务报 告, 2013年, 其全球跨境电商交易额预计为1050亿美元, 未来 5 年内有望增长近 3 倍, 达到 3070 亿美元。其五大跨 境电子商务目标市场对中国商品的网购需求在 2013 年预 计达679亿人民币, 至 2018 年, 这一数字预计将翻两倍, 激增至 1440 亿人民币。报告同时显示, 移动跨境网购市 场规模的增速高于整体跨境电商市场规模的增速, 仅美 国单一市场的移动跨境网购消费总人数, 将在 2018 年超 过2500万。美国尼尔森公司还针对美国、英国、中国、 澳大利亚、巴西、德国所做的调查报告显示，2013年来 自这六大市场的 9370 万消费者, 通过跨境电商消费了约
1050 亿美元。其中, 中国消费者跨境在线采购的规模高 达351.9亿美元，从事跨境电商的公司约20万家。据权威 机构统计, 2014 年度, 约有 $75 \%$ 的海外采购商使用在线外 贸平台进行采购, 约 $84 \%$ 的海外采购商会在未来 $1 \sim 2$ 年内 增加使用这种在线采购方式进行进口的预算, 采购方式 已经逐渐向在线方式转变, 倾向于小单多频与定制化。 从这些分析和数据可以看到, 新的消费需求推动了企业 的变革, 越来越多的企业采用的跨境电商的经营模式, 来迎接新的机遇和挑战。

对于跨境电商来说, 这些数据确实看上去很美, 但深 入进去从事这一行业的人会迅速发现, 从业者是否能真正 成为这些数据中受益的一分子, 似乎没有看上去那么简单, 
跨境电商的爆发式增长对网购、国际贸易、物流运输、仓 储配送、跨境结算等服务, 提出了极为严峻的考验, 以及 其后的售后、退换货、跨境电商信用、风险等问题逐渐凸 显, 成为制约跨境电商发展的瓶颈问题。通过与阿里巴巴 和阿斯特跨境电商的合作, 我们深切感受到目前跨境电商 的发展, 亟待解决四大瓶颈问题。

\section{2. 一是境外 “好商好货” 的货源问题很难控制 和解决}

在这个以流量和销量为王的网络世界里, 境外 “好商 好货” 的货源是不会在一棵树上吊死的，而往往做网店就 是卖的一个信息不对称, 只要是投资者所处城市的实体零 售终端没有批量上架该类产品, 投资者就可以选择周边的 批发市场进货, 省去路费不说, 即使更换货物也很方便。 在非跨境电商模式下，投资者货源多数来源于集散地进货、 批发市场采购、品牌代销。但是这些采购模式对于跨境电 商而言, 都有实现上的巨大差距。在中国国内许多城市, 都有一些大型的商品批发市场或集散地, 那里有不少物美 价廉、品种齐全的商品, 也不乏著名品牌, 在这种模式下 与供应商接触相对比较容易, 也便于沟通和商议, 比如退 换货事宜, 如果出现质量问题时也能顺利解决。做得好的 品牌代销不需多少资金投入，不用准备仓库，不用负责物 流, 不用给商品拍照, 可以从商家那拿到很好的商品图片, 更容易吸引买家。但品牌代销正因为这些优点, 也使得利 润相对缩水, 只能赚取代销差价。另外, 有些个人网店直 接从网上品牌代理商那进货, 作为品牌产品的三级、四级 代理商, 由供应商直接发货给客户, 很难对商品的质量、 库存和售后服务进行把握和控制。

\section{3. 二是单件小批量网购与国际贸易大宗货物进 口通关的问题，包括通关手续流程和物流运 输配送等问题}

去年，国家出台了《关于实施支持跨境电子商务零售 出口有关政策意见的通知》。今年7月份, 国家海关总署 发文, 明确对跨境电商的监管原则, 如规定企业应提交货 物清单，采取 “清单核放、汇总申报” 方式办理进出境货 物报关手续。国家政策的扶持, 行业发展的迅猛, 使得很 多传统企业纷纷涉足跨境电商这一领域, 但是具体实施过 程中, 涉及到的政策更新、资质审核时, 其配套资源匮乏、 流程繁琐等问题, 让很多企业感觉到应该能办但确实不好 办。同时也催生了一些专业的机构为企业提供一站式的跨 境电商服务, 服务包括提供跨境仓储、海外仓储、报关、 海外转运及海外代购等业务。

随着人们海外购物需求的逐年递增, 大量散装商品以 邮政小包、航空小包的形式通关, 但目前还没有专门针对 跨境电商的通关规则, 如果还是以传统外贸通关方式申报 通关, 不仅直接影响跨境电商的交易效率, 也大大增加海 关的监管难度。中国目前大多数中小企业都是委托报关机 构代理通关, 其本身并没有进出口经营权, 而跨境网络零 售没有报关单, 无法申报出口退税和进口纳税, 而且如果
发生退货或返修则直接视为进口, 要缴纳进口关税, 这对 毛利本来就很低的出口电商企业来说, 是难以承受的。

跨境物流没有任何一家物流公司能在全球每一个地 方都做到最好, 全球各地物流环境千差万别, 海关情况也 不一样, 在这些实际运营过程中, 很多时候要靠长期积累 的实际数据去理解在什么样的国家应该用什么样的方式, 全球物流系统流程不是为跨境电商所量身订制的, 需要各 跨境电商去适应。而目前在邮政包裹占据七成份额的情况 下, 跨境电商物流依旧存在种种弊端, 这些弊端是当下平 台经营中不可避免的问题，单件小批量网购与国际贸易大 宗货物运输的矛盾还将长期存在, 亟待解决。

\section{4. 三是跨境电商的交易信用和结算问题, 包括 交易安全和外汇及汇率问题}

国际支付是跨境交易的重要环节, 由于涉及到外汇 资金收付和相关结汇业务, 安全性一直被交易双方所关 注。目前国际上应用最广泛的支付方式为以银行转账、 银联汇款、国际信用卡为代表的传统线下支付工具和以 PayPal为代表的互联网支付工具。随着人们网购习惯的 养成与移动终端的普及, 国际贸易形式将由B2B迅速向 $\mathrm{B} 2 \mathrm{C}$ 和 $\mathrm{C} 2 \mathrm{C}$ 转化, 线上支付和移动支付也必将成为未来跨 境电商的主要变革趋势。但跨境支付的发展也伴随着风 险不确定性增加, 从而对支付企业在安全性和风险把控 方面提出了更高的要求。在中国国内电商领域, 由支付 宝、财付通和银联电子支付组成的第三方在线支付市场 格局已基本形成，三样支付方式占据了 $84.44 \%$ 的中国国 内市场份额。2013年, 上海自贸区成立后, 陆续有 22 家 第三方支付企业获得了跨境电商外汇支付业务的试点牌 照。支付宝除了与万事达合作共同建立反盗版、反欺诈 的安全风险管理机制, 进一步降低阿里巴巴跨境B2C业务 欺计率之外, 还将业务迅速拓展到移动支付端, 与中国 支付通达成合作，在东盟、日本等国推广支付宝钱包的 当面付业务（包括二维码和条形码支付）。

有数据表明, 有 $90 \%$ 的消费者担心跨雯交易的安全性, 在跨境电子支付服务中, 信用安全风险往往是由于交易对 象没有履行约定承诺或者擅自单方面毁约造成的, 而网上 交易时买卖双方都有可能不遵守诚信原则。也没有一部成 熟的和统一的跨境信用标准, 来应对虚拟网络用户信息的 真实度和不确定性, 从而导致消费者及银行不能及时和充 分地了解交易对象的信用情况。由于用户在注册时可能使 用虚假信息，在交易过程中可以使用匿名交易，这就导致 跨境电商交易和资金流向无法审核和监管，为犯罪集团提 供了便利。并且各个国家的信用标准不一致, 这也大大影 响了跨境电商的健康发展。

\section{5. 四是跨境电商退换货和售后服务问题解决困 难}

在中国国内电子商务因为信用安全问题还在顾虑之 际, 跨境电商也出现了诸如假冒伪劣产品、侵犯知识产权 等问题而被海关扣留事件, 而一些中国国内知名外贸电商 
网站也发生了信用欺诈事件。跨境电商交易是通过互联网 完成的, 商品实体及质量如何? 买家单凭网络根本无法知 道, 万一由于质量或运输问题导致消费者对商品不满意, 却因为跨国交易各种限制使得自身的利益无法维护，从而 造成消费者对跨境电商企业的不信任。“恶名市场”是美 国贸易代表办公室2006年提出的一个名词，从2011年2月 起，该办公室开始对外发布详细的名单。此举旨在 “提高 公众意识, 并指导相关的贸易执法行动”。目前已经是第 三次发布了。该名单中汇集了全世界最 “臭名昭著” 的侵 权和假冒伪劣产品市场渠道, 显示这些市场和公司在美国 主流商业市场中的声誉。与北京的秀水街、义乌的小商品 市场等著名的仿冒产品集散地一样, 多家中国互联网公司 曾经名列这份不光彩的名单中。2011年2月，该名单第一 次发布时, 百度、淘宝和 $91 . \mathrm{com}$ 都榜上有名, 当年的 10 月份第二次名单发布, 淘宝继续榜上有名, 百度和 $91 . \mathrm{com}$ 已从名单中被剔除, 搜狗 (音乐) 、狗狗则新进入了名单。 如今, 淘宝和搜狗终于离开了这个 “恶名市场” , 但滕讯 旗下的拍拍入选、迅雷及狗狗也继续榜上有名, 这种办法 一定程度上可以逆制商品质量的原头, 但无法根除跨境电 商退换货和售后服务困难的问题。

\section{6. 结论}

要使跨境电商行业健康稳定的发展下去, 亟待解决以 上四大问题, 并需建立和完善跨境电商的配套体系, 支持 跨境电商企业在海外建供应商仓库, 对货物转仓和越仓信 息要便于客户查询, 同时支持跨境电商企业建立和统一管 理中国国内保税区仓库, 打击非法走私和经营, 对跨境电 商企业的运营进行实质性扶持和监管, 将进出口贸易与跨 境电商完美的结合起来, 实现跨境电商 “好商好货” 两步 走的方式, 即进口货物在中国国内建供应商保税区仓库, 网购征税, 走中国国内电商流程, 出口货物在中国以外国 家建供应商保税区仓库, 网购退税, 走国外电商流程, 从 而实现跨境电商健康有序发展。

\section{参考文献}

１１＼cjkstart吴明华， “先发货后销售” : 跨境电商引领物流新变革, $[\mathrm{J}]$ ，中国远洋航务，2014年12期。

[2] 王碧宏, 大数据时代下跨境电商发展的影响因素研究, [J], 佳木斯职业学院学报, 2014年12期。
[3] 蜂语无声, 2015跨境电商: 高富帅的游戏, [Z], 阿里云资 讯网 www. aliyun. com/zixun/content/2_9_1889036. html。

[4] 林智勇, 2015年中国跨境电商8大发展趋势分析, [Z], 赢

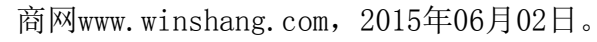

[5] 张无忌, 对国内跨境电商的纯干货分析, [Z], TECH2IP0 创见网http://tech2ipo. com/100494。

[6] 董鹏, 国内跨境电商前景探析, [Z], 中国储运网 www. chinachuyun. com，2014年9月。

[7] 崔玉波, 电商价格大战与供应商管理, [J], 石油石化物资 采购, 2012年第11期。

[8] 张建平, 王默儒, 跨境电商: 中国经济变革新引擎, [Z], 天下网商跨界论坛, 2015 年第 $1 / 2$ 期。

[9] 王军海, 中国跨境电商业务平台选择及跨境物流现状和趋 势分析, [J], 科学时代, 2015年第4期。

[10] 张夏恒, 马天山, 中国跨境电商物流困境及对策建议, $[\mathrm{J}]$, 当代经济管理，2015年5期。

[11] 李金龙, 义乌跨境电商保税物流平台的探索， [J]，中国流 通经济，2015年第7期。

[12] 蔡晶, 我国跨境电子商务发展分析及建议, [J], 商业经济 研究，2015年12期。

[13] 严圣阳, 我国跨境电商支付现状与发展前景, $[\mathrm{J}]$, 经营与 管理，2014年第5期。

[14] 王明宇, 廖秦, 我国跨境电商的主要问题和对策研究, [J], 中国商贸，2014年11期。

[15] 刘佳琪, 电商快递供应商评价及选择方法研究, [D], 北京 邮电大学, 2015年1月。

[16] 宋新伟, 跨境电商人民币结算政策管理框架研究, [J], 时 代金融，2015年08期。

[17] 袁丽, 跨境电商平台的大学生网络创业模式探析, $[\mathrm{J}]$, 江 苏商论, 2014年12期。

[18］关桂峰 秦华江 商意盈, 跨境电商发展之困, $[\mathrm{N}]$, 金融世 界，2015年第2期。

[19] 张卉, 跨境电商发展的SWOT分析及对策, [J], 山东工商学 院学报，2015年6月。 